\title{
Structural Variations in (001)-Oriented Layered Lead Halide Perovskites, Templated by 1,2,4-Triazolium
}

Yuan-Yuan Guo, Lin-Jie Yang, Jason A. McNulty, Alexandra M. Z. Slawin and Philip Lightfoot*

School of Chemistry and EaStChem, University of St Andrews, St Andrews, KY16 9ST, United Kingdom

*e-mail: pl@st-andrews.ac.uk

\begin{abstract}
A new hybrid lead(II) halide perovskite, $(\mathrm{TzH})_{2} \mathrm{PbCl}_{4},\left(\left[\mathrm{TzH}^{+}\right]=1,2,4-\right.$ triazolium), adopts a (001)-oriented layered perovskite structure, which can be considered as derived from the $n=1$ Ruddlesden-Popper (RP) type. Variable temperature single crystal X-ray diffraction reveals a structural phase transition in the region $125 \mathrm{~K}$ $<\mathrm{T}<173 \mathrm{~K}$ between a high temperature, high symmetry polymorph, space group $\mathrm{Cmcm}$, and a low temperature, low symmetry chiral polymorph, space group $P 2{ }_{1}{ }_{2}{ }_{2}{ }_{1}$, which has a tripled unit cell volume. UV-Vis spectra suggest a band gap of $3.30 \mathrm{eV}$ for $(\mathrm{TzH})_{2} \mathrm{PbCl}_{4}$. A second polymorph of the bromide analogue, $(\mathrm{TzH})_{2} \mathrm{PbBr}_{4}-\mathrm{II}$, is also reported, and structural relationships between all three variants are discussed.
\end{abstract}

\section{Introduction:}

Layered perovskites play a key role in functional materials due to their enormous structural flexibility, outstanding physical and chemical properties, particularly in hybrid lead(II) halide perovskites (LHPs). Their impressive performances in electronic and photophysical applications such as light-emitting devices (LEDs) ${ }^{1}$ and solar cells are well documented..$^{2,3}$ By slicing the cubic perovskite aristotype $\mathrm{ABX}_{3}$ along the (001) direction and inserting additional species between these layers, two very well-known families of layered perovskites can be derived, viz. Dion-Jacobson (DJ) and Ruddlesden-Popper (RP) families with general compositions $\mathrm{A}^{\prime} \mathrm{A}_{\mathrm{n}-1} \mathrm{~B}_{\mathrm{n}} \mathrm{X}_{3 \mathrm{n}+1}$ and $\mathrm{A}_{\mathrm{n}+1} \mathrm{~B}_{\mathrm{n}} \mathrm{X}_{3 \mathrm{n}+1}$, respectively. ${ }^{4}$ Here, we report a new hybrid LHP, $(\mathrm{TzH})_{2} \mathrm{PbCl}_{4}\left(" \mathrm{~T}_{2} \mathrm{PbCl}_{4}{ }^{\prime}\right),\left(\left[\mathrm{TzH}^{+}\right]=1,2,4\right.$-triazolium), which adopts the (001)-oriented layered perovskite structure type, and can be considered as a $n=1$ Ruddlesden-Popper 
derivative. This compound displays an interesting change in structure on cooling, leading to a complex superlattice below $\sim 170 \mathrm{~K}$. The nature of this structural change is tracked by single crystal X-ray diffraction and is shown to be related to a reduction of structural frustration mediated by ordering of the $\left(\left[\mathrm{TzH}^{+}\right]\right.$moieties coupled with an octahedral tilting and a buckling of the $\left[\mathrm{PbCl}_{4}\right]_{\infty}$ layers. Subsequent to our recent report of the bromide analogue $(\mathrm{TzH})_{2} \mathrm{PbBr}_{4}$ $\left(" \mathrm{~T}_{2} \mathrm{PbBr}_{4}{ }^{\prime \prime}\right),{ }^{5}$ we have also obtained a second polymorph, "T $\mathrm{TbBr}_{4}-\mathrm{II}^{\prime}$, and structural comparisons are made across each of these polymorphs.

\section{Experimental}

\section{Synthesis}

1,2,4-triazole $\left(\mathrm{C}_{2} \mathrm{H}_{3} \mathrm{~N}_{3}, 99 \%\right)$, lead (II) chloride $\left(\mathrm{PbCl}_{2}, 99 \%\right)$, lead (II) bromide $\left(\mathrm{PbBr}_{2}, \geq 98 \%\right)$ and hydrobromic acid ( $\mathrm{HBr}, 48 \%$, w/w aqueous solution) were purchased from Alfa Aesar. Diethyl ether $\left(\left(\mathrm{C}_{2} \mathrm{H}_{5}\right)_{2} \mathrm{O}, 99.5 \%\right)$ was purchased from Sigma Aldrich. Hydrochloric acid $(\mathrm{HCl}$, $37 \%$, w/w aqueous solution) was purchased from Fisher Chemical. All chemicals were directly used without further purification.

$\mathbf{T}_{2} \mathbf{P b C l}_{4}\left(\mathbf{C}_{4} \mathbf{H}_{8} \mathbf{N}_{6} \mathbf{P b C l}_{4}\right)$, 1,2,4-triazole (690 mg, $10 \mathrm{mmol}$ ) and $\mathrm{PbCl}_{2}$ (556 mg, $2 \mathrm{mmol}$ ) were dissolved in conc. $\mathrm{HCl}(10 \mathrm{~mL})$ with moderate heating. By cooling for a few hours, colourless, plate-shaped crystals were obtained. These crystals were filtered and washed with diethyl ether (yield $62 \%$ based on $\mathrm{PbCl}_{2}$ ). Elemental analysis: (Anal. Calc. (\%) for $\mathrm{T}_{2} \mathrm{PbCl}_{4}$ : $\mathrm{C}, 9.82 ; \mathrm{H}$, 1.65; N, 17.18. Found: C, 9.77; H, 1.60; N, 17.01).

$\mathbf{T}_{2} \mathbf{P b B r}_{4}-\mathrm{II}\left(\mathbf{C}_{4} \mathbf{H}_{8} \mathbf{N}_{6} \mathbf{P b B r}_{4}\right), \mathrm{PbBr}_{2}(734 \mathrm{mg}, 2 \mathrm{mmol})$ and 1,2,4-triazole (138 $\left.\mathrm{mg}, 2 \mathrm{mmol}\right)$ and were dissolved in conc. $\mathrm{HBr}(3 \mathrm{~mL})$ with slow stirring and moderate heating. By cooling overnight, plate-shaped, bright yellow crystals were obtained. These crystals were then collected by filtering and washed several times with diethyl ether (yield $27 \%$ based on $\mathrm{PbBr}_{2}$ ). Elemental analysis: (Anal. Calc. (\%) for $\mathrm{T}_{2} \mathrm{PbBr}_{4}$ : C, 7.20; H, 1.21; N, 12.60. Found: C, 7.38; $\mathrm{H}, 1.14 ; \mathrm{N}, 12.49)$.

\section{Characterisation}

Single crystal X-ray diffraction data were collected on a Rigaku XtaLAB P200 diffractometer at $93 \mathrm{~K}$ and $125 \mathrm{~K}$ and on a Rigaku SCX Mini diffractometer at $173 \mathrm{~K}$ and $298 \mathrm{~K}$ using Mo$\mathrm{K}_{\alpha}$ radiation $\left(\lambda=0.71075 \AA\right.$ ). Data were collected using CrystalClear (Rigaku) software. ${ }^{6}$ Structures were solved by direct methods using SHELXT, ${ }^{7}$ and full-matrix least-squares 
refinements on $\mathrm{F}^{2}$ were carried out using SHELXL-2018/3 ${ }^{7}$ incorporated in the WinGX program. ${ }^{8}$ Absorption corrections were performed empirically from equivalent reflections on the basis of multi-scans by using CrystalClear. ${ }^{6}$ Non-H atoms were refined anisotropically and hydrogen atoms were treated as riding atoms. The high resolution (synchrotron) X-ray diffraction data for crystalline powder of $\mathrm{T}_{2} \mathrm{PbCl}_{4}$ were collected on the beamline I-11 (High Resolution Powder Diffraction) ${ }^{9}$ at the DIAMOND Light Source, Oxford (Rietveld refinement provided in ESI). The energy of X-rays utilised was approximately $12.5 \mathrm{keV}$ with a corresponding wavelength of $1.0008(1) \AA$. The MAC detector was utilised within a $2 \theta$ range of $0-150^{\circ}$ for 2 minutes. Ambient temperature solid UV-Vis absorbance spectra were collected on a JASCO-V550 ultraviolet-visible spectrophotometer with the wavelength range at $200 \mathrm{~nm}$ to $900 \mathrm{~nm}$. Thermal gravimetric analysis (TGA) was carried out for $\mathrm{T}_{2} \mathrm{PbCl}_{4}$ using a Stanton Redcroft STA-780 instrument. The data were collected within the temperature range of 20 to $250{ }^{\circ} \mathrm{C}$ with a heating rate of $5^{\circ} \mathrm{C} / \mathrm{min}$ in air (data provided in ESI).

\section{Results and Discussion}

Crystal structure of $\mathrm{T}_{2} \mathrm{PbCl}_{4}$ at 298 and $173 \mathrm{~K}\left(\mathrm{HT}-\mathrm{T}_{2} \mathrm{PbCl}_{4}\right)$

Single crystal XRD at both 298 and $173 \mathrm{~K}$ reveal a layered perovskite-like structure, with single layers of corner-linked $\mathrm{PbCl}_{6}$ octahedra forming a layer stoichiometry $\left[\mathrm{PbCl}_{4}\right]_{\infty}$, which are separated by a double layer of the $\left[\mathrm{TzH}^{+}\right]$moieties (Figure 1). There is some degree of structural frustration apparent in the model presented, as evidenced by the disorder of the $\left[\mathrm{TzH}^{+}\right]$around a mirror plane and also the elongated thermal ellipsoids of the in-plane $\mathrm{Cl}(2)$ ligand. Although there is no evidence of long-range ordering of octahedral rotations at these temperatures these ellipsoids are perhaps an indication of localised octahedral rotations around the $c$-axis, which can be modelled by splitting of the $\mathrm{Cl}(2)$ position leading to a marginal improvement in R-factors. For the present discussion we prefer to retain the ordered model presented in Figure 1 and Tables 1 and 2. The $\left[\mathrm{TzH}^{+}\right]$moieties form strong hydrogen bonds $(\mathrm{N}-\mathrm{H}---\mathrm{Cl}<3.2 \AA$, Table S5) with the apical chloride, $\mathrm{Cl}(1)$, with no further H-bonding either to in-plane $\mathrm{Cl}(2)$ or between $\left[\mathrm{TzH}^{+}\right]$cations. Figure $1(\mathrm{c})$ shows that neighbouring $\left[\mathrm{PbCl}_{4}\right]_{\infty}$ layers along the $c$-axis are staggered relative to each other in a style that is reminiscent of the RP family, rather than the DJ family. Both these families were originally named based on purely inorganic (oxide) variants, not hybrids. ${ }^{10,11}$ Here we are using RP and DJ to mean 'fully 
staggered' or 'fully eclipsed' neighbouring $\left[\mathrm{PbCl}_{4}\right]_{\infty}$ layers, respectively; i.e. assuming a layer stacking along the $c$-axis, neighbouring layers have a relative displacement of $(1 / 2,1 / 2,0)$ in the RP family whereas the corresponding displacement for the DJ family is $(0,0,0)$. Note that we are aware of further complications in the DJ family, as displacements of $(1 / 2,0,0)$ are also observed in some oxides. ${ }^{10}$ Although there is some discussion in the literature regarding the use of the terms RP and DJ in describing different families of hybrid perovskites, ${ }^{12}$ the nature of the staggering of adjacent layers is a useful starting point for structural comparisons, as it allows a more systematic approach in using symmetry mode analysis ${ }^{13}$ to identify key types of structural distortion. For example, in this case, an idealised 'parent' model can be used to understand and quantify the relative disposition of the adjacent $\left[\mathrm{PbCl}_{4}\right]_{\infty}$ layers, in addition to any other distortion modes present. The parent model is constructed from the aristotype $n=1$ RP phase $\mathrm{K}_{2} \mathrm{NiF}_{4}$ (tetragonal, space group $I 4 / \mathrm{mmm}$ with idealised unit cell metrics $a_{\mathrm{RP}}, c_{\mathrm{RP}}$ ), using only the ' $\left[\mathrm{NiF}_{4}\right]$ ' atomic coordinates to mimic the present $\left[\mathrm{PbCl}_{4}\right]_{\infty}$ layer. Further details are given in Table S9 in ESI. The online suite ISODISTORT ${ }^{14}$ provides a normal mode analysis of the contributing distortion modes, based on deviations of the observed crystal structure from the parent. In this case, it is readily apparent that the unit cell of $\left(\mathrm{HT}-\mathrm{T}_{2} \mathrm{PbCl}_{4}\right)$ has a superlattice $a \sim \sqrt{ } 2 a_{\mathrm{RP}}, b \sim \sqrt{ } 2 a_{\mathrm{RP}}, c \sim c_{\mathrm{RP}}$, relative to the parent structure. The only significant distortion mode is a mode of symmetry $\mathrm{M}_{5}^{-}$, which acts, most importantly, to displace adjacent layers in an 'alternating' (antiferrodistortive) manner along the $b$-axis relative to the 'fully staggered' case by $\Delta \mathrm{y} \sim 0.19$ (i.e. $1.4 \AA$ ), and simultaneously allows a minor 'scissoring' distortion of the in-plane $\mathrm{Pb}-\mathrm{Cl}(2)$ geometry.
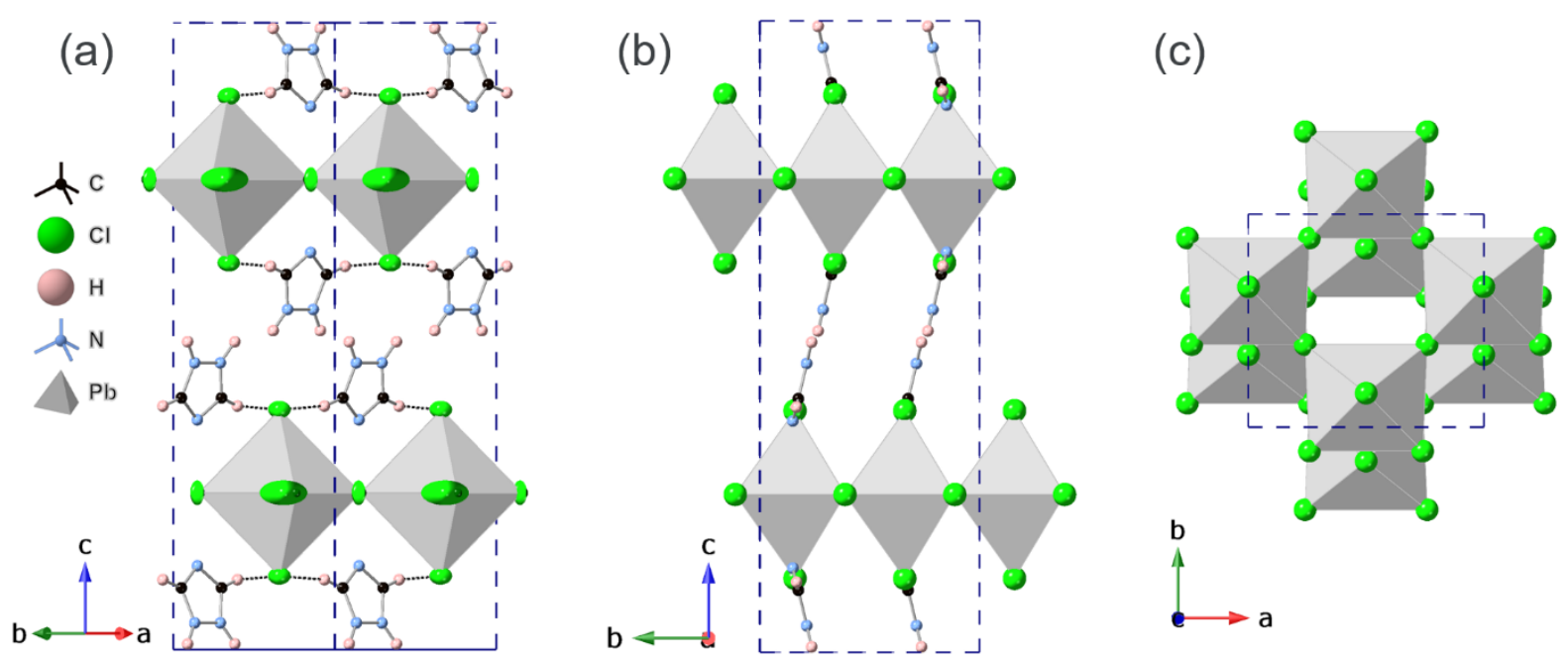

Figure 1. Unit cell packing and hydrogen-bonding scheme for $\mathrm{T}_{2} \mathrm{PbCl}_{4}$ at $173 \mathrm{~K}$, space group $C m c m$ (a) along the $a b$-plane, (b) along the $a$-axis and (c) along the $c$-axis. Note that thermal ellipsoids are shown for the $\mathrm{Cl}$ atoms only in (a). 
Table 1. Crystal and Structure Refinement Data for $\mathrm{T}_{2} \mathrm{PbCl}_{4}$ and $\mathrm{T}_{2} \mathrm{PbBr}_{4}-\mathrm{II}$.

\begin{tabular}{|c|c|c|c|}
\hline Temperature & $\mathrm{T}_{2} \mathrm{PbCl}_{4}(173 \mathrm{~K})$ & $\mathrm{T}_{2} \mathrm{PbCl}_{4}(93 \mathrm{~K})$ & $\mathrm{T}_{2} \mathrm{PbBr}_{4}-\mathrm{II}(173 \mathrm{~K})$ \\
\hline Formula & $\mathrm{C}_{4} \mathrm{H}_{8} \mathrm{~N}_{6} \mathrm{PbCl}_{4}$ & $\mathrm{C}_{4} \mathrm{H}_{8} \mathrm{~N}_{6} \mathrm{PbCl}_{4}$ & $\mathrm{C}_{4} \mathrm{H}_{14} \mathrm{~N}_{4} \mathrm{PbBr}_{4}$ \\
\hline Formula weight & 489.15 & 489.15 & 666.99 \\
\hline Colour/Habit & Colourless/Platelet & Colourless/Platelet & Yellow/Block \\
\hline Crystal size $\left(\mathrm{mm}^{3}\right)$ & $0.24 \times 0.13 \times 0.06$ & $0.04 \times 0.03 \times 0.01$ & $0.22 \times 0.18 \times 0.13$ \\
\hline Crystal system & Orthorhombic & Orthorhombic & Monoclinic \\
\hline Space group & $\mathrm{Cmcm}$ & $P 2{ }_{1}{ }_{1} 2_{1}$ & $P 2{ }_{1} / c$ \\
\hline$a(\AA)$ & $8.3060(5)$ & $8.313(4)$ & $9.6451(7)$ \\
\hline$b(\AA)$ & $7.4959(5)$ & $21.426(9)$ & $8.4001(5)$ \\
\hline$c(\AA)$ & $21.5814(17)$ & $21.959(8)$ & $8.3932(5)$ \\
\hline$\beta\left({ }^{\circ}\right)$ & 90 & 90 & $97.016(8)$ \\
\hline$V\left(\AA^{3}\right)$ & $1343.68(16)$ & $3911(3)$ & $674.92(8)$ \\
\hline$Z$ & 4 & 12 & 2 \\
\hline$\rho_{\text {calc }}\left(\mathrm{g} / \mathrm{cm}^{3}\right)$ & 2.418 & 2.492 & 3.282 \\
\hline$\mu\left(\mathbf{m m}^{-1}\right)$ & 13.331 & 13.739 & 22.958 \\
\hline$F(000)$ & 896 & 2688 & 592 \\
\hline Reflns collected & 5412 & 50108 & 5445 \\
\hline & 651 & 7112 & 1172 \\
\hline Independent reflns & {$[\mathrm{R}(\mathrm{int})=0.0506]$} & {$[\mathrm{R}(\mathrm{int})=0.0754]$} & {$[\mathrm{R}($ int $)=0.0484]$} \\
\hline Goodness of Fit & 1.235 & 0.892 & 1.083 \\
\hline Final $R$ indices $(I>2 \sigma(D)$ & $\mathrm{R}_{1}=0.0269$ & $\mathrm{R}_{1}=0.0314$ & $\mathrm{R}_{1}=0.0263$ \\
\hline FInal K Inaices $(1>2 \sigma(1))$ & $\mathrm{wR}_{2}=0.0616$ & $\mathrm{wR}_{2}=0.0691$ & $\mathrm{wR}_{2}=0.0668$ \\
\hline Largest diff. peak/hole (e $\AA^{-3}$ ) & $1.191 /-1.471$ & $1.780 /-2.181$ & $2.279 /-1.081$ \\
\hline
\end{tabular}

Table 2. Selected bond lengths $(\AA)$ and bond angle $\left(^{\circ}\right)$ ranges for $\mathrm{T}_{2} \mathrm{PbCl}_{4}$ at $173 \mathrm{~K}(\mathrm{HT}), 93$ $\mathrm{K}(\mathrm{LT})$, and $\mathrm{T}_{2} \mathrm{PbBr}_{4}-\mathrm{II}$ at $173 \mathrm{~K}$. Octahedral distortion parameters, $\Delta d$ and $\sigma^{2}{ }^{15,16}$ are also provided.

\begin{tabular}{|c|c|c|c|c|c|}
\hline $\mathbf{A B X}_{3}$ & HT-T ${ }_{2} \mathrm{PbCl}_{4}$ & $\begin{array}{c}\mathrm{LT}- \\
\mathrm{T}_{2} \mathrm{PbCl}_{4}(\mathrm{~Pb} 1) \\
\end{array}$ & $\begin{array}{c}\mathrm{LT}- \\
\mathrm{T}_{2} \mathrm{PbCl}_{4}(\mathrm{Pb2}) \\
\end{array}$ & $\begin{array}{c}\text { LT- } \\
\mathrm{T}_{2} \mathrm{PbCl}_{4}(\mathrm{Pb3}) \\
\end{array}$ & $\mathrm{T}_{2} \mathrm{PbBr}_{4}-\mathrm{II}$ \\
\hline \multirow{6}{*}{ Pb-X (Å) } & $2.764(3)$ & $2.788(5)$ & $2.800(5)$ & $2.791(5)$ & $2.993(1)$ \\
\hline & $2.764(3)$ & $2.808(5)$ & $2.813(4)$ & $2.809(5)$ & $2.993(1)$ \\
\hline & $2.841(3)$ & $2.841(4)$ & $2.857(4)$ & $2.845(4)$ & $2.995(1)$ \\
\hline & $2.841(3)$ & $2.882(4)$ & $2.864(4)$ & $2.874(5)$ & $2.995(1)$ \\
\hline & $2.868(3)$ & $2.882(5)$ & $2.879(5)$ & $2.874(5)$ & $3.001(1)$ \\
\hline & $2.868(3)$ & $2.886(5)$ & $2.880(5)$ & $2.883(4)$ & $3.001(1)$ \\
\hline \multirow{3}{*}{$\mathrm{X}-\mathrm{Pb}-\mathrm{X}\left({ }^{\circ}\right)$} & $84.23(1)$ & $81.08(18)$ & $80.85(18)$ & $80.42(17)$ & $83.26(2)$ \\
\hline & to & to & to & to & to \\
\hline & $102.90(3)$ & $109.33(16)$ & $109.38(15)$ & $109.59(15)$ & $96.74(2)$ \\
\hline
\end{tabular}




\begin{tabular}{cccccc}
$\mathbf{P b}-\mathbf{X}-\mathbf{P b}\left({ }^{\circ}\right)$ & $172.90(3)$ & $169.90(2)$ & $145.95(19)$ & $170.90(2)$ & $165.12(3)$ \\
& & $145.30(2)$ & $170.41(19)$ & $145.70(19)$ & \\
$* \boldsymbol{\Delta} \boldsymbol{d}\left(\times \mathbf{1 0}^{-4}\right)$ & 2.43 & 1.85 & 1.20 & 1.51 & 0.01 \\
$* \boldsymbol{\sigma}^{\mathbf{2}}$ & 25.67 & 47.72 & 48.31 & 49.50 & 26.18 \\
\hline
\end{tabular}

* The octahedral distortion parameters are defined according to: the bond length distortion, $\Delta d=\left(\frac{1}{6}\right) \sum\left[\frac{d_{n}-d}{d}\right]^{2}$, where $d$ is the average $\mathrm{Pb}-\mathrm{X}$ bond distance of each octahedron, $d_{\mathrm{n}}$ is the individual bond distance. ${ }^{15}$ The bond angle variance, $\sigma^{2}=\sum_{i=1}^{12} \frac{\left(\theta_{i}-90\right)^{2}}{11}$ was calculated as a distorted level of each octahedron from an ideal, undistorted structure $\left(90^{\circ}\right)$, where $\theta_{i}$ is the X$\mathrm{Pb}-\mathrm{X}$ angle. ${ }^{16}$

\section{Crystal structure of $\mathrm{T}_{2} \mathrm{PbCl}_{4}$ at 125 and $93 \mathrm{~K}\left(\mathrm{LT}-\mathrm{T}_{2} \mathrm{PbCl}_{4}\right)$}

On cooling to 125 and $93 \mathrm{~K}$ the crystal structure of $\mathrm{T}_{2} \mathrm{PbCl}_{4}$ is seen to change to a more distorted variant with a larger unit cell and a chiral space group, $P 2{ }_{1} 2{ }_{1} 2_{1}$ (Table 1, Figure 2). There are now three symmetry-inequivalent $\mathrm{PbCl}_{6}$ octahedra and six unique $\left[\mathrm{TzH}^{+}\right]$moieties. The RPlike arrangement of layers remains intact, but the supercell metrics are now approximately $a^{\prime} \sim$ $\sqrt{ } 2 a_{\mathrm{RP}}, b^{\prime} \sim c_{\mathrm{RP}}, c^{\prime} \sim 3 \sqrt{ } 2 a_{\mathrm{RP}}$, relative to the parent structure (i.e. $a^{\prime} \sim a, b^{\prime} \sim c, c^{\prime} \sim 3 b$, relative to the HT- $\mathrm{T}_{2} \mathrm{PbCl}_{4}$ structure). It can be seen (Figure 2(c)) that the $\mathrm{M}_{5}{ }^{-}$mode (antiferrodistortive displacement of neighbouring layers relative to the fully staggered parent) is still the dominant distortion mode, but three further significant modes are now activated. The first of these $\left(\mathrm{X}_{2}^{+}\right)$ is a cooperative rotation of the $\mathrm{PbCl}_{6}$ octahedra around the $b$-axis, seen clearly in Figure 2(b). Recall that the structure of $\mathrm{HT}-\mathrm{T}_{2} \mathrm{PbCl}_{4}$ shows highly anisotropic behaviour of the in-plane $\mathrm{Cl}$ ligands; it is now clear that these localised displacements condense out to a long-range ordered state on cooling through the HT-LT transition. The second pair of significant distortion modes (designated $\Delta_{3}$ and $\mathrm{Y}_{3}$ in ISODISTORT) that appear below this phase transition are related, and together define a sinusoidal 'rippling' of the $\left[\mathrm{PbCl}_{4}\right]_{\infty}$ layers, leading to the tripled unit cell along $c$, which can be seen most clearly in schematic form in Figure 3. It should be noted that this distortion is distinct from the more normal 'octahedral tilt' mode ubiquitous in perovskites and, as far as we are aware, is unique in layered perovskites. All the $\left[\mathrm{TzH}^{+}\right]$moieties form strong hydrogen bonds ( $\mathrm{N}-\mathrm{H}---\mathrm{Cl}<3.2 \AA$, Table S6, S7) with the apical chloride, as was also present in $\mathrm{HT}-\mathrm{T}_{2} \mathrm{PbCl}_{4}$. The driving force for the structural phase transition is presumably related to relief of strain in $\mathrm{HT}-\mathrm{T}_{2} \mathrm{PbCl}_{4}$, with concomitant ordering of the $\left[\mathrm{TzH}^{+}\right]$moieties to 
optimise H-bonding opportunities, which further drives the cooperative octahedral tilting and 'rippling' of the $\left[\mathrm{PbCl}_{4}\right]_{\infty}$ layers.
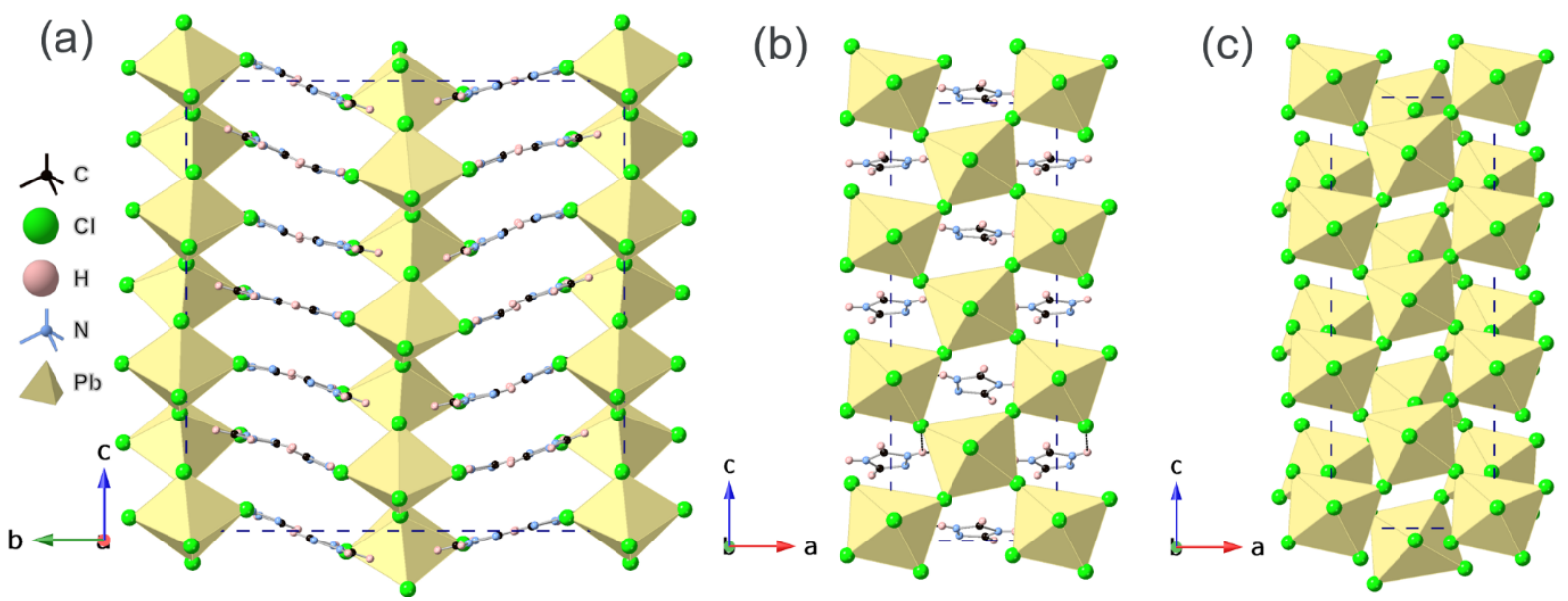

Figure 2. Unit cell packing and hydrogen-bonding scheme for $\mathrm{T}_{2} \mathrm{PbCl}_{4}$ at $93 \mathrm{~K}$, space group $P 2{ }_{1} 2{ }_{1}{ }_{1}$ (a) along the $a$-axis, (b) along the $b$-axis and (c) staggering of the adjacent layers.

(a)

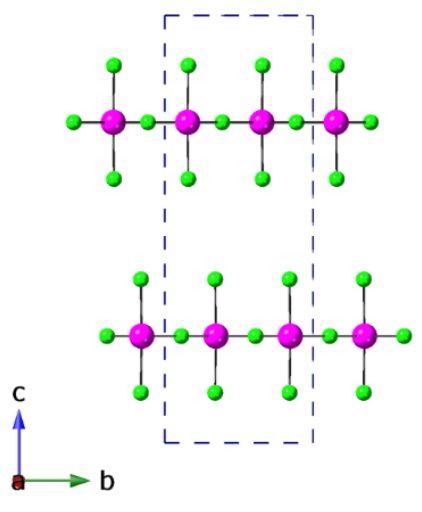

(b)

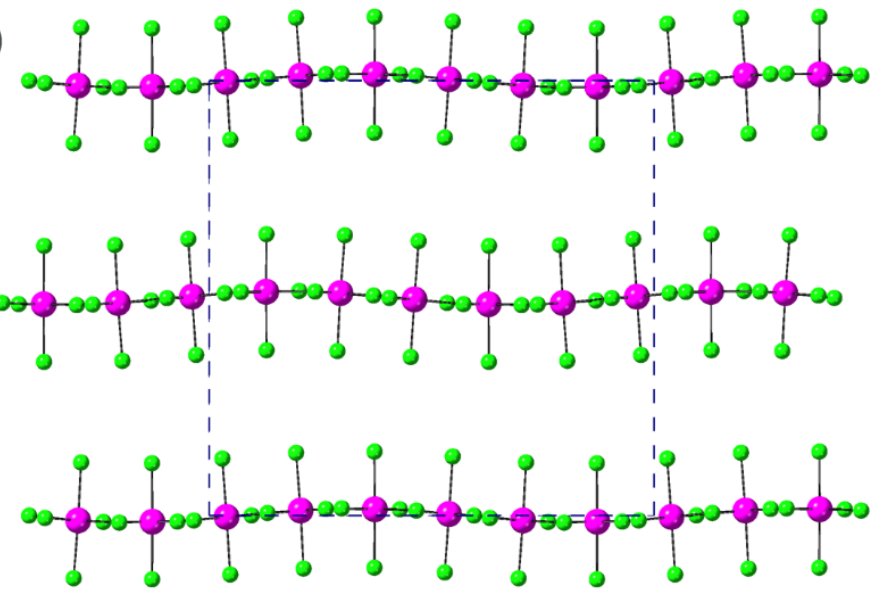

Figure 3. Comparison of the $\left[\mathrm{PbCl}_{4}\right]_{\infty}$ layers in (a) $\mathrm{HT}-\mathrm{T}_{2} \mathrm{PbCl}_{4}$ and (b) $\mathrm{LT}_{-} \mathrm{T}_{2} \mathrm{PbCl}_{4}$. Note that sinusoidal buckling of the $\left[\mathrm{PbCl}_{4}\right]_{\infty}$ layers in $\mathrm{LT}-\mathrm{T}_{2} \mathrm{PbCl}_{4}$ leading to a unit cell tripling.

\section{UV-Vis spectra}

Preliminary UV-vis absorbance spectra were carried out for $\mathrm{T}_{2} \mathrm{PbCl}_{4}$ powder sample at wavelengths between $200 \mathrm{~nm}$ to $900 \mathrm{~nm}$ (Figure 4). The absorption spectra reveal that $\mathrm{T}_{2} \mathrm{PbCl}_{4}$ features two absorption peaks at $\sim 335 \mathrm{~nm}(3.7 \mathrm{eV})$ and $\sim 358 \mathrm{~nm}(3.5 \mathrm{eV})$. The band gap of 
$3.30 \mathrm{eV}$ was derived from the Tauc-Plot (inset Figure 4(a)). The value is larger than the previous reported bromide counterpart, $\mathrm{T}_{2} \mathrm{PbBr}_{4}-\mathrm{I}(2.68 \mathrm{eV})$, and agrees well with the feature of band gap trends of $\mathrm{Br}<\mathrm{Cl}$ in similar materials. ${ }^{17,18}$

(a)

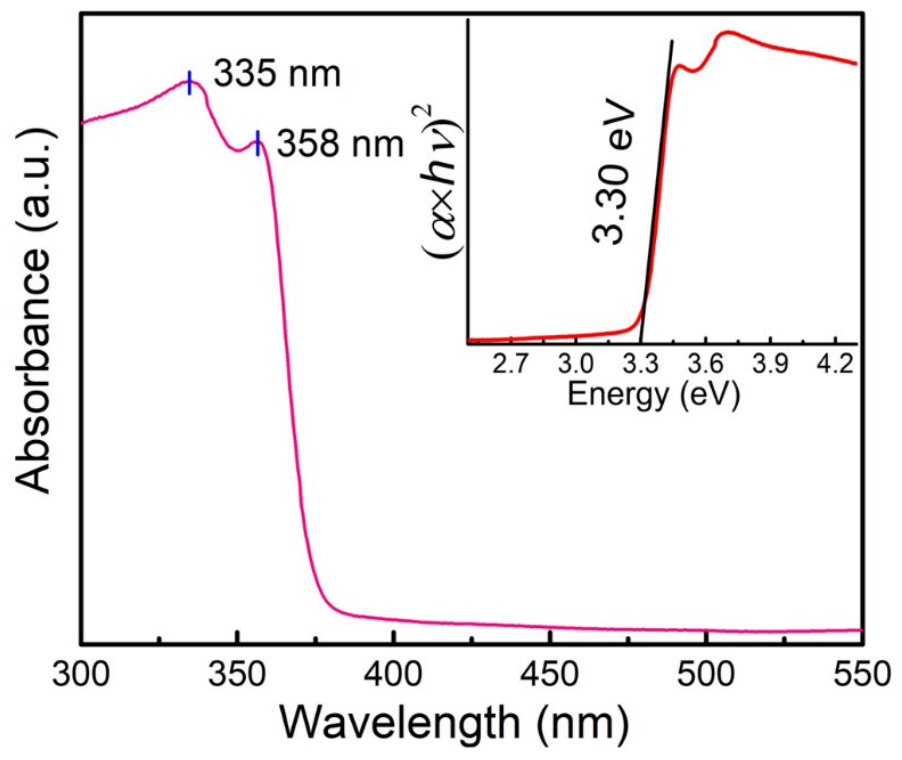

(b)

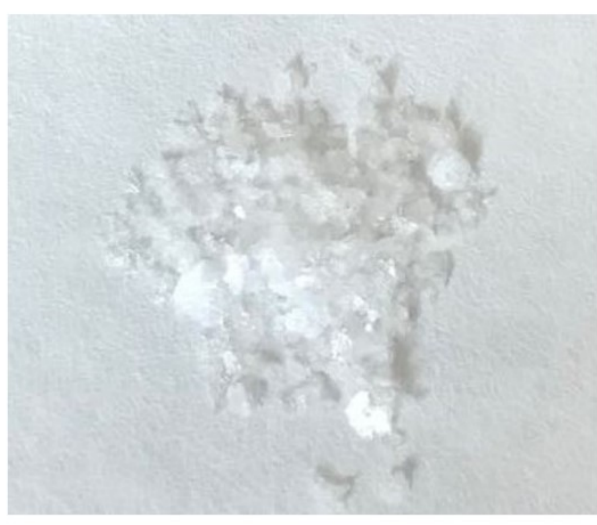

Figure 4. (a) UV absorption spectra and Tauc-Plot (inset) of $\mathrm{T}_{2} \mathrm{PbCl}_{4}$, (b) $\mathrm{T}_{2} \mathrm{PbCl}_{4}$ crystals.

\section{Crystal structure of $\mathrm{T}_{2} \mathrm{PbBr}_{4}-\mathrm{II}$ at $173 \mathrm{~K}$}

We recently reported the crystal structure and photophysical behaviour of the first polymorph of $\mathrm{T}_{2} \mathrm{PbBr}_{4} .^{5}$ That polymorph (now referred to as $\mathrm{T}_{2} \mathrm{PbBr}_{4}-\mathrm{I}$ ) was shown to have a layered perovskite-like structure more closely related to the DJ rather than RP family, exhibiting neareclipsed $\left[\mathrm{PbBr}_{4}\right]_{\infty}$ layers. The unit cell of $\mathrm{T}_{2} \mathrm{PbBr}_{4}-\mathrm{I}$ has monoclinic symmetry, space group $C 2 / c$ at both 173 and $298 \mathrm{~K}$, with no evidence of any temperature-induced phase transitions in this region. The unit cell metrics of $\mathrm{T}_{2} \mathrm{PbBr}_{4}$-I are approximately $a \sim 11.9 \AA\left(\sim 2 a_{\mathrm{DJ}}\right), b \sim 11.9$ $\AA\left(\sim 2 a_{\mathrm{DJ}}\right), c \sim 19.2 \AA\left(\sim 2 c_{\mathrm{DJ}}\right), \beta \sim 95^{\circ}$ at $173 \mathrm{~K}$, where the parameters in brackets represent the relationship of the unit cell to the aristotype DJ parent phase (typified by $\mathrm{TlAlF}_{4}$, tetragonal, $P 4 / m m m$, metrics $\left.a_{\mathrm{DJ}}, c_{\mathrm{DJ}}\right)$. However, our initial reactions aimed at a $\left[\mathrm{TzH}^{+}\right]$-containing lead bromide, with a slightly different reactant ratio (see the Experimental section), produce a different polymorph of the same composition, designated $\mathrm{T}_{2} \mathrm{PbBr}_{4}$-II, which we now describe. 
$\mathrm{T}_{2} \mathrm{PbBr}_{4}$-II also exhibits a DJ-related structure (Figure 5), but has a simpler variant, with a smaller unit cell than $\mathrm{T}_{2} \mathrm{PbBr}_{4}-\mathrm{I}$. Crystallographically, there is only a single $\mathrm{Pb}$ site and a single $[\mathrm{TzH}]^{+}$site. In this case, neighbouring layers occur in a near-eclipsed arrangement and, whilst octahedral tilting does occur, the nature of this is distinct from that in $\mathrm{T}_{2} \mathrm{PbBr}_{4}-\mathrm{I}$; a combination of these effects leads to a unit cell for $\mathrm{T}_{2} \mathrm{PbBr}_{4}$-II of approximately $a \sim 9.6 \AA\left(\sim c_{\mathrm{DJ}}\right), b \sim 8.4$ $\AA\left(\sim \sqrt{2} a_{\mathrm{DJ}}\right), c \sim 8.4 \AA\left(\sim \sqrt{2} a_{\mathrm{DJ}}\right), \beta \sim 97^{\circ}$ at 173 (Table 1). The unit cell volume of $\mathrm{T}_{2} \mathrm{PbBr}_{4}-\mathrm{I}$ is therefore approximately four times that of $\mathrm{T}_{2} \mathrm{PbBr}_{4}-\mathrm{II}$, suggesting that $\mathrm{T}_{2} \mathrm{PbBr}_{4}-\mathrm{I}_{\text {may }}$ be the thermodynamically stable phase. In fact, all our further attempts to reproduce the " $\mathrm{T}_{2} \mathrm{PbBr}_{4}$ " composition, based on reaction mixtures of slightly different composition, produced $\mathrm{T}_{2} \mathrm{PbBr}_{4}-$ I, but not $\mathrm{T}_{2} \mathrm{PbBr}_{4}-\mathrm{II}$, supporting the suggestion that the former may be the more thermodynamically stable polymorph under such reaction conditions.
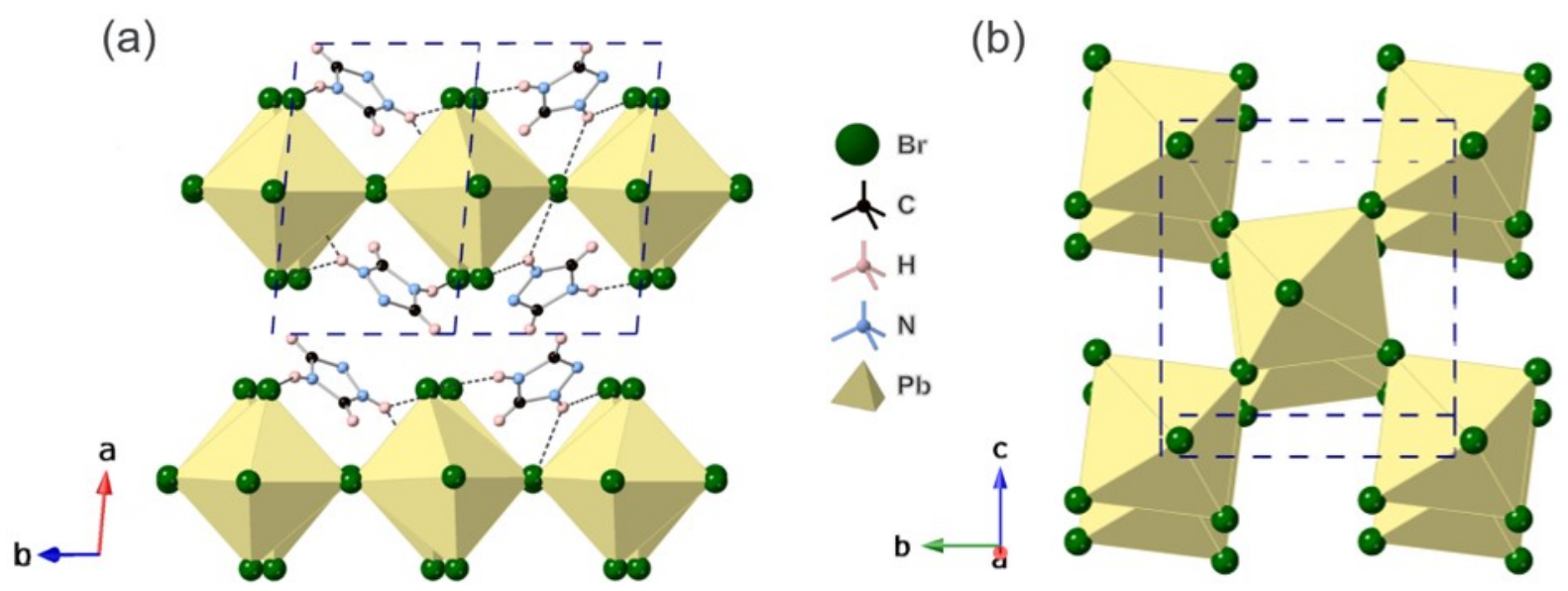

Figure 5. Unit cell packing and hydrogen-bonding scheme for $\mathrm{T}_{2} \mathrm{PbBr}_{4}-\mathrm{II}$ at $173 \mathrm{~K}$, space group $P 2{ }_{1} / c$ (a) along the $b c$-plane and (b) perpendicular to the $b c$-plane.

Considering the octahedral tilting within the two polymorphs, the various options have been classified for $\mathrm{A}_{2} \mathrm{BX}_{4} \mathrm{RP}$ phases and $\mathrm{ABX}_{4} \mathrm{DJ}$ phases by Aleksandrov et al. ${ }^{19}$, and in adapted Glazer-like notation by Li et al. ${ }^{20}$ In the notation of Li et al. ${ }^{20}$ the tilt system of $\mathrm{T}_{2} \mathrm{PbBr}_{4}-\mathrm{II}$ is $\mathrm{a}^{-} \mathrm{a} \mathrm{c}$, signifying rotation of octahedra around the $a$-axis and out-of-phase tilting of adjacent octahedra along each of the in-plane axes. This tilt system is analogous to the well-known ' $\mathrm{GdFeO}_{3}$-type' tilt system in conventional 3D perovskites and also appears to be relatively common in LHPs. [Note that the corresponding tilt system for structures with full 3D connectivity is designated as $\mathrm{a}^{-} \mathrm{a}^{-} \mathrm{c}^{+}$, but it is evident that the '+' superscript is not relevant in single-layered materials. Instead, we use ' $c$ ' to mean rotated, whereas $c^{0}$ would mean not rotated and (-c) would mean rotated in opposite senses in adjacent layers]. In contrast, the tilt 
system in $\mathrm{T}_{2} \mathrm{PbBr}_{4}-\mathrm{I}$ is much less common and may be described as $\mathrm{a}^{-} \mathrm{b}^{0} \mathrm{c} / \mathrm{a}^{-} \mathrm{b}^{0} \mathrm{c}$, signifying inphase rotation of octahedra around the $c$-axis and out-of-phase tilting of adjacent octahedra along only one of the in-plane axes; for structures with two layers per unit cell, the symbol describes the behaviour of the two adjacent layers. The eclipsing of adjacent $\left[\mathrm{PbBr}_{4}\right]_{\infty}$ layers in $\mathrm{T}_{2} \mathrm{PbBr}_{4}$-II leads to noticeably short inter-layer $\mathrm{Br}---\mathrm{Br}$ non-bonded contacts of 4.088(1) $\AA$.

Selected geometrical parameters for each structure are provided in Table 2. It can be seen, in particular, that the $\mathrm{HT}-\mathrm{LT}$ transition in $\mathrm{T}_{2} \mathrm{PbCl}_{4}$ leads to significantly more distorted $\mathrm{PbCl}_{6}$ octahedra in the LT polymorph, and also to a greater diversity of bridging $\mathrm{Pb}-\mathrm{Cl}-\mathrm{Pb}$ angles.

We also attempted to prepare the iodide analogue, $(\mathrm{TzH})_{2} \mathrm{PbI}_{4}\left(" \mathrm{~T}_{2} \mathrm{PbI}_{4}\right.$ "), using similar reactions to those above. However, we have not yet been able to produce this composition. Instead, we have prepared a composition $\mathrm{T}_{4} \mathrm{~Pb}_{3} \mathrm{I}_{10} \cdot 2 \mathrm{H}_{2} \mathrm{O}$, which adopts the $\mathrm{Cs}_{4} \mathrm{Mg}_{3} \mathrm{~F}_{10}$ structure type. $^{21}$ This unusual structure contains layers composed of trimers of face-sharing octahedra, further linked by corner-sharing. It is rare amongst LHPs, but has been seen, for example in (TMA) $)_{4} \mathrm{~Pb}_{3} \mathrm{Cl}_{10},{ }^{22}$ (TMS) ${ }_{4} \mathrm{~Pb}_{3} \mathrm{Br}_{10},{ }^{23}$ (DMTE) ${ }_{4} \mathrm{~Pb}_{3} \mathrm{Br}_{10}{ }^{24}$ and (BIT) $)_{4} \mathrm{~Pb}_{3} \mathrm{I}_{10}{ }^{25}$ Further details of this structure are provided in the ESI.

In summary, we have described our exploratory studies towards preparation of compounds of the composition $(\mathrm{TzH})_{2} \mathrm{PbX}_{4}$, $\left(\left[\mathrm{TzH}^{+}\right]=1,2,4\right.$-triazolium, $\left.\mathrm{X}=\mathrm{Cl}, \mathrm{Br}, \mathrm{I}\right)$. Both $\mathrm{T}_{2} \mathrm{PbCl}_{4}$ and $\mathrm{T}_{2} \mathrm{PbBr}_{4}$ are shown to adopt (001)-oriented layered perovskite structures, but differ in the nature of the staggering of adjacent octahedral layers (i.e. near-RP versus near-DJ type). Moreover, $\mathrm{T}_{2} \mathrm{PbCl}_{4}$ is shown to display a phase transition to a complex superstructure with a unique 'rippled' octahedral layer at low temperature; the phase transition is apparently triggered by ordering the organic moieties, breaking mirror symmetry, which co-operates with a freezing-out of a disordered octahedral tilt mode, ultimately leading to a more stable $\mathrm{H}$ bonding configuration. On the contrary, $\mathrm{T}_{2} \mathrm{PbBr}_{4}$ is found to crystallise in two distinct polymorphs related to the DJ family, which exhibit distinct octahedral tilting systems, but with no evidence of a temperature induced phase transition. So far, we have been unable to prepare the iodide analogue, $\mathrm{T}_{2} \mathrm{PbI}_{4}$, instead obtaining a more complex composition, with a rare structure type. It is noteworthy, from both the present work and previous studies using small disc-shaped amines with more than one nitrogen atom, ${ }^{26-29}$ such as triazolium, imidazolium and guanidinium as templates, that the diversity of $\mathrm{H}$-bonding opportunities offered by these species encourages a variety of competing structure types and polymorphic forms. Clearly, the synthetic and structural chemistry within this family of materials is complex and apparently 
outcomes are finely balanced between polymorphs with similar stability, thus making further in-depth synthetic and crystallographic studies of related composition spaces an attractive target.

\section{Conflicts of interest}

The authors declare no conflict of interest.

\section{Supplementary data}

\section{Acknowledgements}

We thank Prof. Chiu Tang for assistance with data collected at Diamond.

We acknowledge support from the University of St Andrews, the China Scholarship Council (studentship to YYG) and Leverhulme Trust (RPG-2018-065).

The research data underpinning this article are available at: https://doi.org/10.17630/8ec43b91782a-4c56-9501-eb7a700e1e48

\section{References}

1 M. D. Smith, B. A. Connor and H. I. Karunadasa, Chem. Rev., 2019, 119, 3104-3139.

2 X. Li, J. Hoffman, W. Ke, M. Chen, H. Tsai, W. Nie, A. D. Mohite, M. Kepenekian, C. Katan, J. Even, M. R. Wasielewski, C. C. Stoumpos and M. G. Kanatzidis, J. Am. Chem. Soc., 2018, 140, 12226-12238.

3 L. Mao, W. Ke, L. Pedesseau, Y. Wu, C. Katan, J. Even, M. R. Wasielewski, C. C. Stoumpos and M. G. Kanatzidis, J. Am. Chem. Soc., 2018, 140, 3775-3783.

4 N. A. Benedek, J. M. Rondinelli, H. Djani, P. Ghosez and P. Lightfoot, Dalton Trans., 2015, 44, 10543-10558.

5 Y. Guo, L. Yang, S. Biberger, J. A. McNulty, T. Li, K. Schötz, F. Panzer and P. Lightfoot, Inorg. Chem., 2020, acs.inorgchem.0c01807.

6 Rigaku, CrystalClear, 2014, Rigaku Corporation, Tokyo, Japan.

7 G. M. Sheldrick, Acta Cryst. C, 2015, 71, 3-8.

$8 \quad$ L. J. Farrugia, J. Appl. Crystallogr., 2012, 45, 849-854. 
9 DIAMOND Light Source website, https://www.diamond.ac.uk/Instruments/Crystallography/I11.html.

10 N. Mercier, Angew. Chemie - Int. Ed., 2019, 58, 17912-17917.

11 M.-H. Tremblay, J. Bacsa, B. Zhao, F. Pulvirenti, S. Barlow and S. R. Marder, Chem. Mater., 2019, 31, 6145-6153.

12 Q. A. Akkerman and L. Manna, ACS Energy Lett., 2020, 604-610.

13 M. I. Aroyo and J. M. Perez-Mato, Phase Transitions, 1997, 63, 235-255.

14 B. J. Campbell, H. T. Stokes, D. E. Tanner and D. M. Hatch, J. Appl. Crystallogr., 2006, 39, 607-614.

15 M. W. Lufaso and P. M. Woodward, Acta Crystallogr. Sect. B Struct. Sci., 2004, 60, $10-20$.

16 K. Robinson, G. V. Gibbs and P. H. Ribbe, Science, 1971, 172, 567-570.

17 X. Li, P. Guo, M. Kepenekian, I. Hadar, C. Katan, J. Even, C. C. Stoumpos, R. D. Schaller and M. G. Kanatzidis, Chem. Mater., 2019, 31, 3582-3590.

18 R. Gautier, M. Paris and F. Massuyeau, J. Am. Chem. Soc., 2019, 141, 12619-12623.

19 K. S. Aleksandrov and J. Bartolomé, Phase Transitions, 2001, 74, 255-335.

20 T. Li, R. Clulow, A. J. Bradford, S. L. Lee, A. M. Z. Slawin and P. Lightfoot, Dalton Trans., 2019, 48, 4784-4787.

21 H. Steinfink and G. Brunton, Inorg. Chem., 1969, 8, 1665-1668.

22 C. Xue, S. Wang, W. L. Liu and X. M. Ren, Chem. - A Eur. J., 2019, 25, 5280-5287.

23 M. D. Smith, B. L. Watson, R. H. Dauskardt and H. I. Karunadasa, Chem. Mater., 2017, 29, 7083-7087.

24 H. J. Li, Y. L. Liu, X. G. Chen, J. X. Gao, Z. X. Wang and W. Q. Liao, Inorg. Chem., 2019, 58, 10357-10363.

25 C. P. Raptopoulou, A. Terzis, G. A. Mousdis and G. C. Papavassiliou, Zeitschrift für Naturforsch. B, 2002, 57, 645-650.

26 Y. Y. Guo, J. A. McNulty, N. A. Mica, I. D. W. Samuel, A. M. Z. Slawin, M. Bühl and 
P. Lightfoot, Chem. Commun., 2019, 55, 9935-9938.

27 O. Nazarenko, M. R. Kotyrba, M. Wörle, E. Cuervo-Reyes, S. Yakunin and M. V. Kovalenko, Inorg. Chem., 2017, 56, 11552-11564.

28 J. A. McNulty and P. Lightfoot, Chem. Commun., 2020, 56, 4543-4546.

29 M. Daub, C. Haber and H. Hillebrecht, Eur. J. Inorg. Chem., 2017, 2017, 1120-1126. 


\section{TOC Graphic}

Two new layered hybrid perovskites are reported. (TzH) ${ }_{2} \mathrm{PbCl}_{4}$ undergoes a unique structural phase transition, due to 'rippling' of perovskite-like layers.

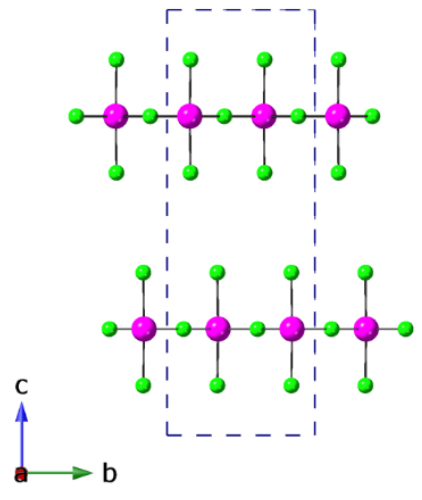

(HT Phase)

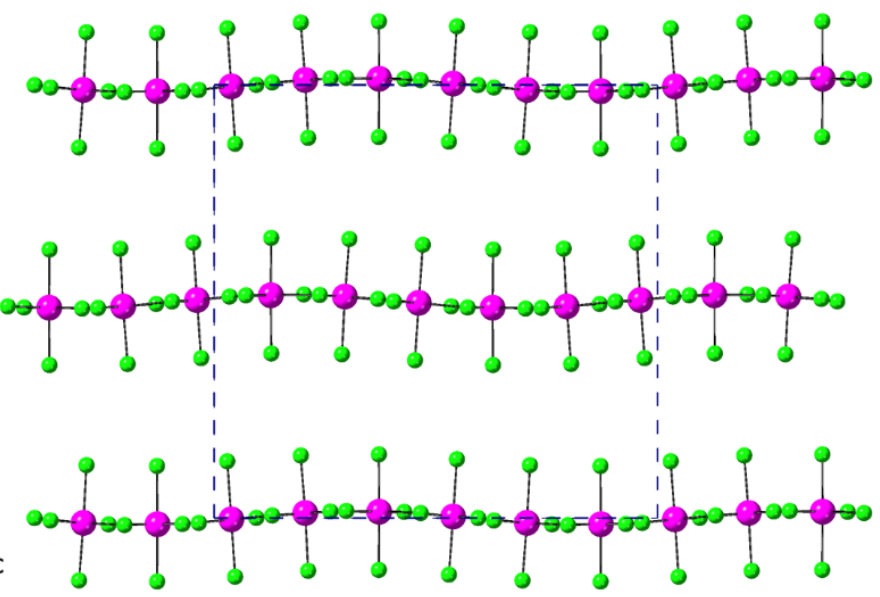

(LT Phase-tripled) 